The Materials Research Society (MRS), in partnership with Cambridge University Press, has been dedicated to providing a continually advancing suite of publications for its members and the materials community.

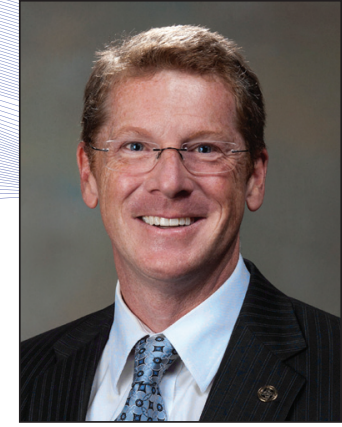

Sean J. Hearne

2018 MRS President

\title{
These are your publications
}

As researchers, scientists, and engineers, one of our most valuable contributions to the advancement of society is the dissemination of our discoveries. As we have all seen, scholarly publication - a primary venue for disseminating scientific discovery — has been going through a renaissance over the past two decades, driven largely by advances in electronic distribution. For example, it is very likely you are reading this MRS Bulletin article with an electronic device rather than in print. And with the plethora of electronic publications comes the blessing and curse of metrics (e.g., impact factors and h-index). I will not venture into the debate of whether these are true bellwethers of future success or simply a foofaraw. Rather, I would argue that it is the sharing of knowledge - allowing the scientific community to discuss, debate, and absorb new information - that is most paramount for advancing our collective world.

Let me share with you some of the 2017 highlights of the MRS publications portfolio, and also offer a look toward the future.

\section{Publications and MRS Meetings, a shared vision}

Do MRS publications influence meeting programming, or does MRS meeting programming influence publications? The answer is both. MRS meetings and publications work in tandem, always on the lookout to bring members and the materials community the most up-to-date information on hot topics such as artificial intelligence and quantum materials. So, if you present at one of the MRS meetings, MRS journal editors are anxious to hear about your research and eager to publish it as well.

\section{MRS Communications}

In 2017, this letters and prospectives journal had an outstanding year. The Impact Factor increased by $68 \%$ to 3.01 . Submissions increased by more than $130 \%$. And Rigoberto C. Advincula was introduced as the new Editor-in-Chief. In 2018, look for a special issue on "2D Materials in Health Care."

\section{MRS Advances}

MRS Advances focuses on delivering rapid reports of work in progress - snapshots of key materials research topics identified by MRS Meeting programming. This newest journal in the MRS portfolio, under the leadership of Editor-in-Chief David F. Bahr, has been accepted for indexing in the Web of Science, Emerging Sources Citation Index (ESCI). In 2018, we look for it to be approved for Impact Factor. 


\section{MRS Bulletin}

The inaugural MRS Bulletin Postdoctoral Publication Prize was awarded to Andy Tay Kah Ping, Stanford University, during the 2017 MRS Fall Meeting. Tay was selected from 120 applicants/nominations for "his combination of outstanding academic credentials, scientific publications, and science communication efforts.” This award complements two existing MRS journal awards - JMR Paper of the Year and the MRS Communications Lecture, both of which are presented annually at the MRS Spring Meeting.

\section{Journal of Materials Research (JMR)}

$J M R$ published seven Focus Issues in 2017, including its second annual "Early Career Scholars in Materials Science" issue. For 2018, that number will increase to 12 , with topics ranging from architected materials to 3D printing of biomaterials. With the addition of new Associate Editor Susmita Bose, Washington State University, JMR plans to further its reach in the biomaterials arena.

\section{MRS Energy \& Sustainability}

This journal addresses broad perspectives in energy and sustainability as they relate to the impact of materials research on society. With expert reviews on controversial topics, articles in this journal are popular with the press and social media, with Altmetric Scores reaching 448 and growing!

\section{Books and Textbooks}

The MRS Books Collection continues to grow, with its newest textbook—Materials Engineering: Bonding, Structure and Structure-Property Relationships-by 2017 MRS President Susan Trolier-McKinstry and Robert E. Newnham, publishing as recently as December.

\section{MRS OnDemand ${ }^{\circledR}$ Webinar Series}

Building on the popularity of the monthly MRS Bulletin Webinars, MRS is expanding its offerings in 2018, focusing on technical topics as well as professional development.

All that being said, while the MRS Board of Directors continues to plan for, and support, the growth and development of the publications program, the most important ingredient is you. I cannot emphasize enough that these are your publications! If you have an idea for a $J M R$ Focus Issue, a hot topic for a webinar, or special issue of MRS Communications, or if you're looking for a volunteer opportunity, please let us know. Together, we can help shape the future of MRS publications, as we contribute to them ... read them ... and celebrate them.
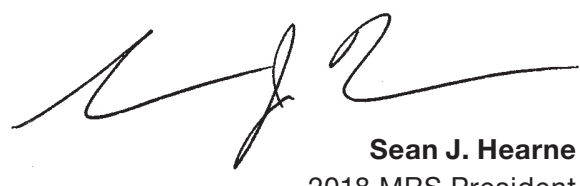

2018 MRS President 